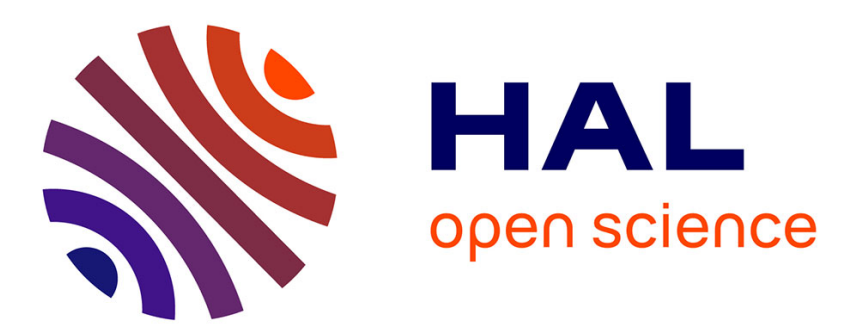

\title{
Thermo-mechanical characterization of the Ti17 titanium alloy under extreme loading conditions
}

Yessine Ayed, Guénaël Germain, Amine Ammar, Benoit Furet

\section{To cite this version:}

Yessine Ayed, Guénaël Germain, Amine Ammar, Benoit Furet. Thermo-mechanical characterization of the Ti17 titanium alloy under extreme loading conditions. International Journal of Advanced Manufacturing Technology, 2016, pp.1-11. 10.1007/s00170-016-9476-5 . hal-01391021

\section{HAL Id: hal-01391021 \\ https://hal.science/hal-01391021}

Submitted on 2 Nov 2016

HAL is a multi-disciplinary open access archive for the deposit and dissemination of scientific research documents, whether they are published or not. The documents may come from teaching and research institutions in France or abroad, or from public or private research centers.
L'archive ouverte pluridisciplinaire HAL, est destinée au dépôt et à la diffusion de documents scientifiques de niveau recherche, publiés ou non, émanant des établissements d'enseignement et de recherche français ou étrangers, des laboratoires publics ou privés. 


\title{
Thermo-mechanical characterization of the Ti17 titanium alloy under extreme loading conditions
}

\author{
Y. Ayed ${ }^{1}$. G. Germain ${ }^{1}$ - A. Ammar' ${ }^{1}$ B. Furet $^{2}$
}

\begin{abstract}
Understanding the physics of chip formation in machining operations is often difficult due to the complexity of the phenomena involved, such as the extreme and complex loading conditions that occur in the cutting zone. In order to model the machining process, it is necessary to use a constitutive behavior law that is capable of reproducing as accurately as possible the behavior of the material under these extreme conditions. In this context, this paper presents a study of the mechanical behavior of the Ti17 titanium alloy at high strain rates and high temperatures. This has been achieved by undertaking compression and shear tests over a wide range of strain rates (from $10^{-1} \mathrm{~s}^{-1}$ to $100 \mathrm{~s}^{-1}$ ) and temperatures (from 25 to $800^{\circ} \mathrm{C}$ ). The results show that the Ti17 alloy is sensitive to strain rate, especially for strain rates greater than $1 \mathrm{~s}^{-1}$. In addition, the alloy retains good mechanical properties at high temperature (up to $500{ }^{\circ} \mathrm{C}$ ). Based on the experimental results, the parameter of the Johnson-Cook constitutive equation have been identified using the inverse method. Some weaknesses in the model have been highlighted after the identification phase, especially in terms of the $m$ and $C$ parameters. A modification of the model has been proposed.
\end{abstract}

Keywords High strain rate $\cdot$ High temperature . Johnson-Cook - Characterization · Titanium alloy . Machining

\section{Introduction}

Titanium alloys are known for their excellent mechanical properties, even at high temperatures, and for their very good strength to weight ratio. This explains the diverse fields of application for these alloys and the particular interest shown by the aeronautical and aerospace industries. However, titanium alloys typically have very poor machinability. To deal with this problem, it is necessary to understand the physics involved in cutting operations and the different phenomena that can occur. Numerical simulation of the cutting process can provide valuable information necessary for the understanding of chip formation $[2,10$, $25,35]$. However, this modeling must accurately represent the physical phenomena involved, and it must reproduce the thermo-mechanical behavior of the material.

Experimental measurement of the temperature in the cutting zone, using various techniques, show that it varies between 700 and $1000{ }^{\circ} \mathrm{C}[1,11,18,24,26]$. In addition, via both analytical and experimental methods, the maximum strain rate in the cutting zone is estimated to be in the range of $10^{3} \mathrm{~s}^{-1}$ to $10^{5} \mathrm{~s}^{-1}$. The generation of heat combined with the high strain rates leads to the localization of the strain and the formation of shear band during chip formation. Hence, in order to simulate the machining process, it is necessary to use a plasticity model that is capable taking into account these phenomena. 
As a general rule, constitutive models can be grouped into three categories [14]: empirical, semi-physical, and physical.

- Empirical constitutive models are usually simple to identify. This facilitates their implementation in computer codes $[3,7,15]$

- Semi-physical constitutive models are more complex and require more experimental tests, the identification is more difficult than the empirical case [20, 22, 36]

- Physical constitutive models are based completely on metallurgical and physical aspects (microstructure, dislocations, recrystallization ...). However, the number of model parameters is typically high and by consequence a large number of experimental tests are required to identify the parameters [5], using sometimes complicated methodologies.

At present, the most widely used constitutive equation for the simulation of dynamic phenomena is the JohnsonCook (JC) equation [15]. This model has several advantages which have lead to its outstanding success. In particular, its mathematical simplicity and the simple identification procedure combined with good prediction accuracy for many physical phenomena. In addition, its implementation by default in many finite element computer codes has also promoted its use.

The Johnson-Cook (JC) equation is shown in Eq. 1. The first term represents the isotropic hardening [19]. The second term represents the sensitivity to the strain rate. The sensitivity to temperature is taken into account by the third term. Parameters $A, B, n, C, m$ are constants that need to be determined experimentally over a wide range of temperatures and strain rates. $\dot{\varepsilon}_{0}, T_{f}$ and $T_{a}$ are the reference strain rate, the melting temperature of the material and the ambient temperature, respectively.

$\sigma=\underbrace{\left(A+B \varepsilon^{n}\right)}_{1} \underbrace{\left(1+C \ln \frac{\dot{\varepsilon}}{\dot{\varepsilon}_{0}}\right)}_{2} \underbrace{\left(1-\left(\frac{T-T_{a}}{T_{f}-T_{a}}\right)^{m}\right)}_{3}$

Nevertheless, many studies have focused about modifying this constitutive equation to take into account different thermomechanical mechanisms in particular the thermal softening and materials behavior at high strain rates. Moreover, various comparative studies have been conducted to compare JC with other constitutive equations $[12,13,17$, $23,28,30,38]$.

The difficulty in implementing and identifying more complex and more efficient material behavior models is an obstacle limiting their wide spread adoption. This makes

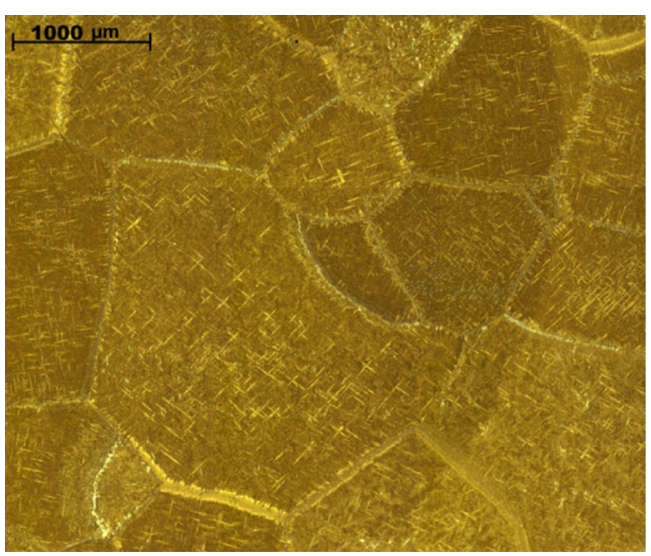

Fig. 1 Microstructure of the as-recieved Ti17 alloy

the use of the JC model indispensable for the simulation of dynamic problems under certain conditions. Hence, the JC model has been used in the present work to model the material behavior of the Ti17 alloy.

\section{Experimental setup}

The study has been carried out on a beta-rich titanium alloy, Ti17 (Ti-5Al-2Sn-4Mo-2Zr-4Cr). At room temperature, it is composed of $\alpha$ and $\beta$ phases. The $\alpha$ phase can exist in different lamellar morphologies: $\alpha$ Grain Boundary $\left(\alpha_{G B}\right), \alpha$ Widmanstätten Grain Boundary $\left(\alpha_{W G B}\right)$ and $\alpha_{W I}$ morphologies [32]. The microstructure of the material is presented in Fig. 1. Table 1 presents the main thermal and mechanical properties of Ti17.

The experimental tests were carried out on a GLEEBLE 3500 thermo-mechanical testing machine. The machine is equipped with a $100 \mathrm{kN}$ load cell. Strain measurements are made using strain gauges. The temperature is measured by a $\mathrm{K}$-type thermocouple. The specimen is placed between two anvils and is heated by the passage of an electric current (Joule effect). All tests were carried out in a vacuum $\left(10^{-5}\right.$ bar). To reduce the friction and to promote the thermal conductivity, graphite paper and a nickel paste are applied to the anvils/specimen interface.

Table 1 Thermal and mechanical properties of Ti17 $\left(25^{\circ} \mathrm{C}\right)$

\begin{tabular}{ll}
\hline Tensile Strength, $\sigma_{U T S}(M P a)$ & 1110 \\
Elongation at Break $(\%)$ & $5-8$ \\
Density, $\rho\left(K g / \mathrm{m}^{3}\right)$ & 4650 \\
Specific heat, $C_{p}\left(\mathrm{~J} / \mathrm{Kg}^{\circ} \mathrm{C}\right)$ & 525 \\
Thermal conductivity, $\lambda\left(\mathrm{W} / \mathrm{m}^{\circ} \mathrm{C}\right)$ & 7 \\
\hline
\end{tabular}




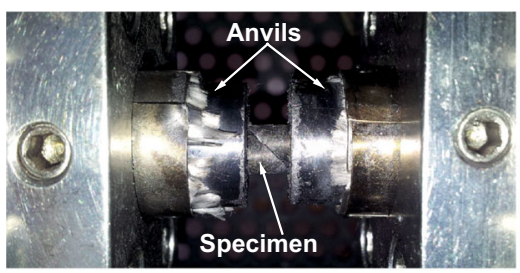

(a)

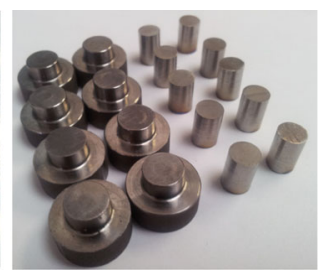

(b)
Fig. 2 a Exprimental setup, b Shear and compression specimens

In order to determine the mechanical behavior of the Ti17 alloy under extreme conditions, both compression and shear tests have been conducted at different strain rates and different temperatures. The tests cover a wide range of strain rates $\left(0.1 \mathrm{~s}^{-1}-100 \mathrm{~s}^{-1}\right)$ and temperatures $\left(25-800{ }^{\circ} \mathrm{C}\right)$. Figure 2 shows the experimental setup and the specimen shapes for the compression and shear tests.

\section{Compression tests}

In order to determine the influence of the strain rate, a series of tests has been carried out with different impact velocities. Figure 3 shows the results of the first series of tests. It can be seen that the Ti17 alloy exhibits a nonlinear response to the strain rate, at ambient temperature. Moreover, the influence of strain rate can be observed for strain rates greater than $1 \mathrm{~s}^{-1}$.

The objective of the second series of tests is to determine the effect of the temperature on the behavior of the Ti17. For this, the temperature has been varied from 25 to

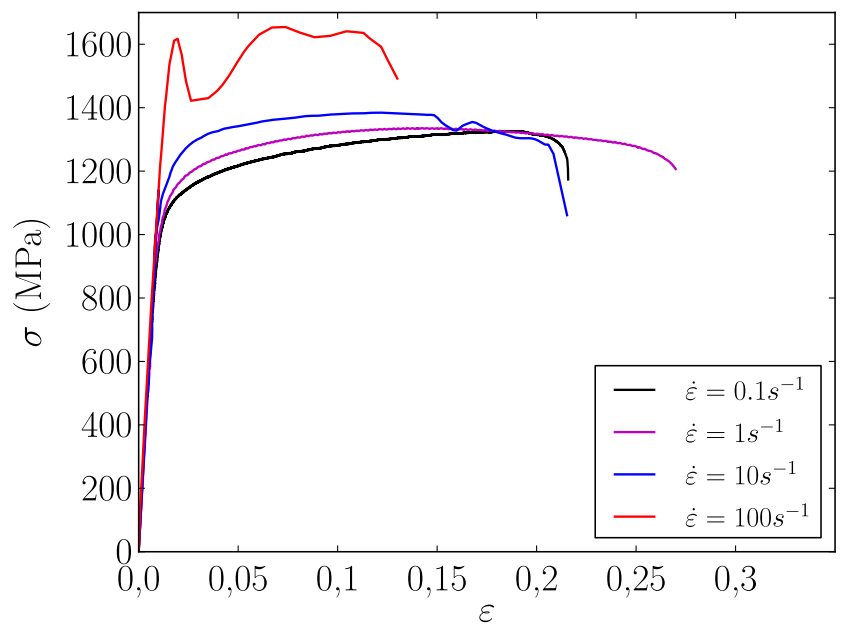

Fig. 3 Influence of strain strain rate $\left(T=25^{\circ} \mathrm{C}\right)$

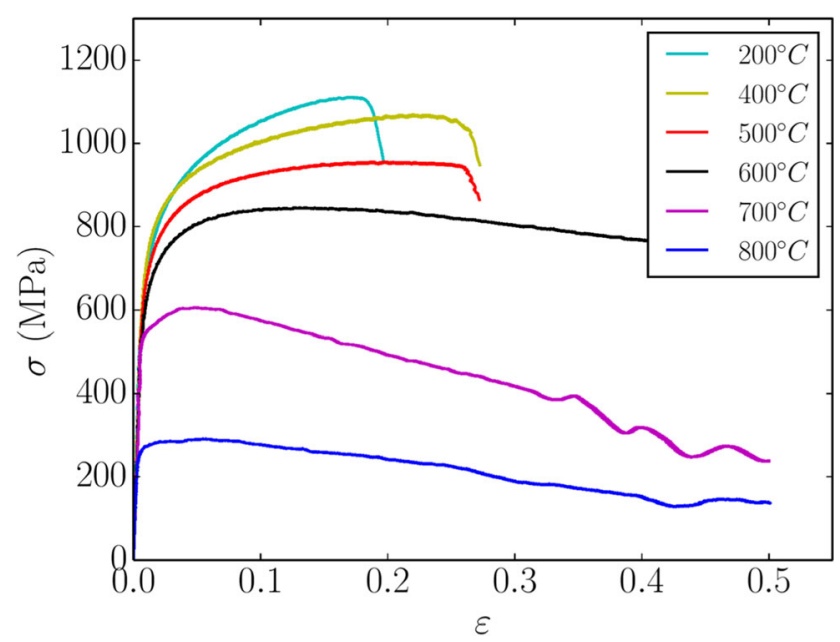

Fig. 4 Influence of temperature $\left(\dot{\varepsilon}=0.1 \mathrm{~s}^{-1}\right)$

$800^{\circ} \mathrm{C}\left(\dot{\varepsilon}=0.1 \mathrm{~s}^{-1}\right)$. The principal results have been plotted in Fig. 4. It can be seen that good mechanical properties are conserved even at high temperatures $\left(500-600{ }^{\circ} \mathrm{C}\right)$. Thermal softening occurs at temperatures greater than $600{ }^{\circ} \mathrm{C}$ and is more pronounced for the tests realized at 700 and $800{ }^{\circ} \mathrm{C}$.

\section{Identification of the model parameters}

The identification procedure for the Johnson-Cook constitutive model is widely documented in the literature [6, $9,16,27,29,33,34,37]$. The range of validity of the

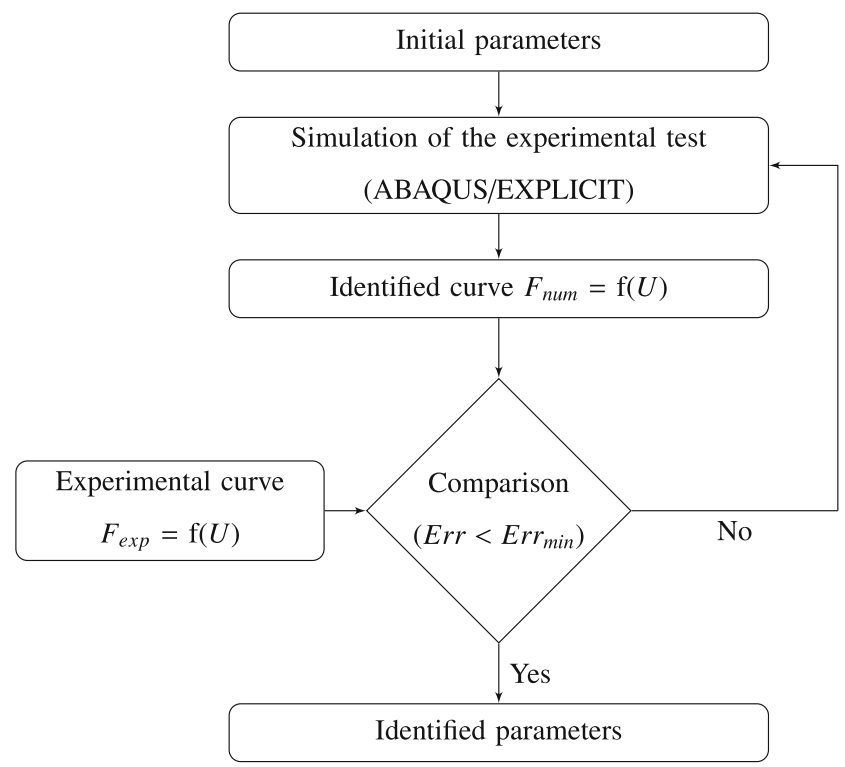

Fig. 5 Identification procedure 


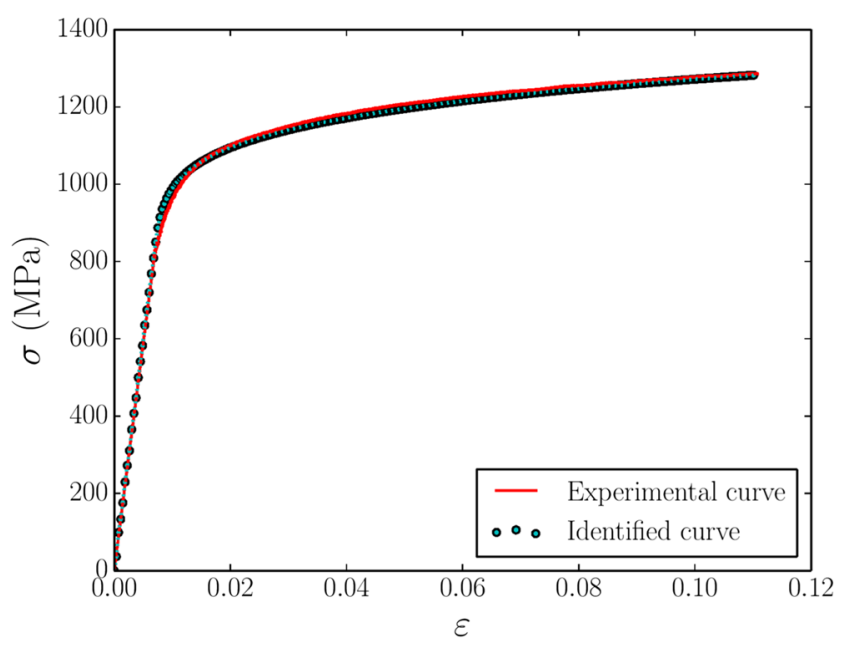

Fig. 6 Comparison of the experimental/identified curves $(A=750$ $\mathrm{MPa}, B=803 \mathrm{MPa}, n=0.17$ )

identified parameters depends on the experimental data in terms of strain rate and temperature. The parameters can be identified by a direct method or an inverse method. The direct method is faster but gives an average estimation for the $C$ and $m$ parameters. In this work, the parameters of the Johnson-Cook law have been identified by an inverse method.

The inverse identification method consists of an iterative procedure in which a numerical stress-strain curve is calculated from a finite element simulation of the mechanical test using the Johnson-Cook constitutive model. For the first iteration, an initial set of parameters is used. The numerical curve is then compared to the experimental curve. An error function is calculated to quantify the difference or error between the two curves. The "Lavemberg-Marquart" optimization algorithm is used to optimize the set of parameter. Thus, the aim of the method is to minimize the relative difference between the numerical curve and the experimental curve. Figure 5 illustrates the identification method.
Table 2 Variation of parameter $m\left(\dot{\varepsilon}=0.1 s^{-1}\right)$

\begin{tabular}{lllll}
\hline Temperature ${ }^{\circ} \mathrm{C}$ & 400 & 600 & 700 & 800 \\
\hline $\mathrm{m}$ & 1.1 & 1.02 & 0.85 & 0.41 \\
\hline
\end{tabular}

The finite element simulation of the experimental tests has been performed using ABAQUS/EXPLICIT. An axisymmetric model with an explicit integration scheme has been adopted. The model has been meshed with four nodes elements and reduced integration (CAX4RT). The friction between the machine anvils and the specimen is neglected. All physical parameters of the material vary as function of the temperature.

Identification of the hardening parameters $(A, B, n)$ The first step consists of identifying the hardening parameters $A, B$, and $n$. For this, tests at a strain rate of $0.1 \mathrm{~s}^{-1}$ have been carried out at room temperature. In this case, the JC equation may be written in the form of Eq. 2 .

$\sigma=A+B \varepsilon^{n}$

The optimum parameters given by the optimization algorithm are $\mathrm{A}=750 \mathrm{MPa}, \mathrm{B}=803 \mathrm{MPa}, n=0.17$. Figure 6 shows the experimental response and the numerical response using these parameters. The difference between these two curves does not exceed $1 \%$. It can be considered that a variation of $5 \%$ in the hardening parameters does not drastically degrade the accuracy of the results.

Sensitivity to the temperature The second step consists of identifying the parameter $m$, which reflects the sensitivity to the temperature. Four temperature levels have been selected: $400,600,700$, and $800{ }^{\circ} \mathrm{C}$. Equation 3 shows the equation to be identified

$\sigma=\left(750+803 \varepsilon^{0,17}\right)\left(1-\left(\frac{T-T_{a}}{T_{f}-T_{a}}\right)^{m}\right)$
Fig. 7 Comparison of the experimental/identified curves: a $m=f(T), \mathbf{b} m=1.02$

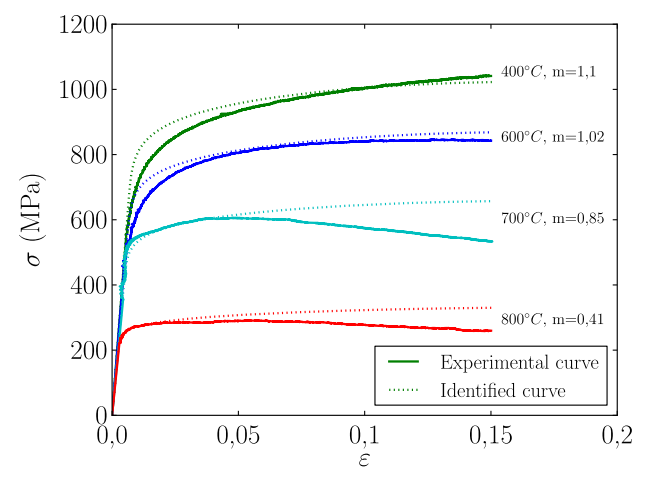

(a)

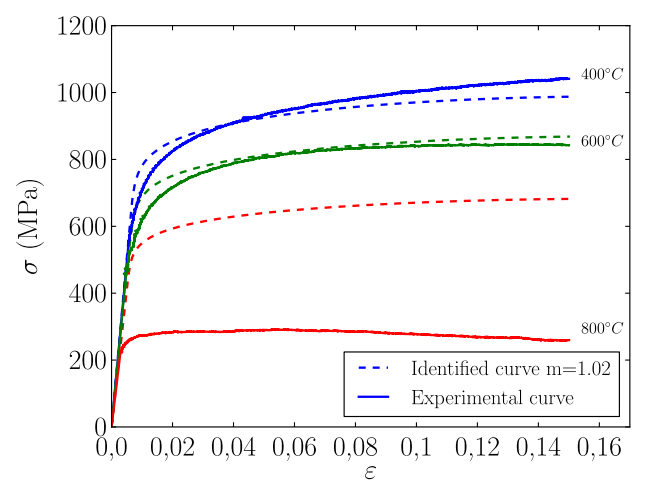

(b) 

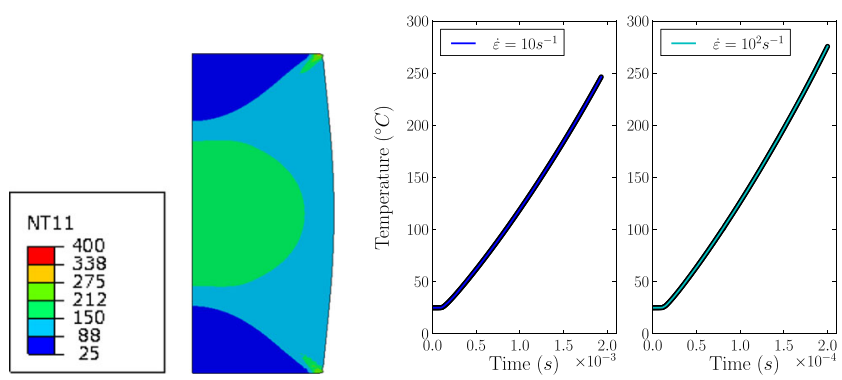

Fig. 8 Temperature evolution in the centre of the specimen (compression tests)

Figure 7 illustrates the obtained results from two different identification strategies. The first one consists of identifying the $m$ parameter for each temperature level (Fig. 7a). The second involves finite element simulations using a constant $m$ parameter. In this case, a significant difference between the experimental and the numerical results can be seen, particularly for temperatures greater than $600{ }^{\circ} \mathrm{C}$ (Fig. 7b). Thus, it can be concluded that parameter $m$ should vary as a function of the temperature to minimize the estimation error Fig. 7b. It is also important to highlight that the JC model is not able to reproduce the thermal softening phenomena that occurs in the studied temperature range.

Table 2 shows the summary of the values of the parameter $m$ as a function of the temperature.

Ti17 sensitivity to strain rate The last step involve the identification of the $C$ parameter which reflects the sensitivity to the strain rate. The strain rate has been varied from $0.1 s^{-1}$ to $100 s^{-1}$. The identification can be performed in two ways.

The first consists of identifying the parameter $C$ without the consideration of the thermal softening due to the heat

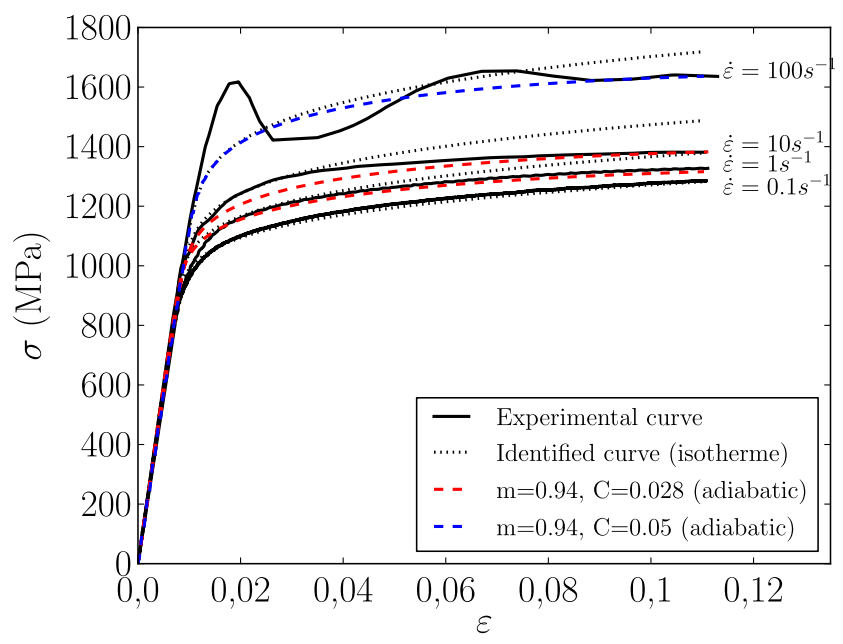

Fig. 9 Comparison of the experimental and identified curves
Table 3 Variation of parameter $C\left(T=25^{\circ} \mathrm{C}\right)$

\begin{tabular}{llll}
\hline$\dot{\varepsilon}\left(\mathrm{s}^{-1}\right)$ & 1 & 10 & 100 \\
\hline $\mathrm{C}$ & 0.028 & 0.028 & 0.05 \\
\hline
\end{tabular}

generated by the plastic deformation. In this case, the JC model can be written as Eq. 4

$\sigma=\left(750+803 \varepsilon^{0,17}\right)\left(1+C \ln \left(\frac{\dot{\varepsilon}}{\dot{\varepsilon}_{0}}\right)\right)$

The second identification approach takes into account thermal softening. Equation 5 shows the temperature change due to plastic deformation. Where $C_{p}, \rho$, and $\beta$ are the heat capacity, density, and Taylor-Quinney coefficient [31], respectively. The Taylor-Quinney coefficient represents the fraction of the plastic deformation energy transformed into heat.

$\Delta T \simeq \beta \int \frac{\sigma \Delta \varepsilon_{p}}{\rho C_{p}}$

From the numerical simulation of the mechanical tests, the maximum temperature reached in the center of the specimen can be calculated (Fig. 8). Hence, the JC model can be written as Eq. 6 .

$$
\begin{aligned}
\sigma= & \left(750+803 \varepsilon^{0,17}\right)\left(1+C \ln \left(\frac{\dot{\varepsilon}}{\dot{\varepsilon}_{0}}\right)\right) \\
& \times\left(1-\left(\frac{(T+\Delta T)-T_{a}}{T_{f}-T_{a}}\right)^{m}\right)
\end{aligned}
$$

Figure 9 shows the results obtained for both cases. For the isothermal curves, the numerical response predicts the beginning of plasticity until a certain maximum stress is reached. It can be seen that thermal softening due to internal
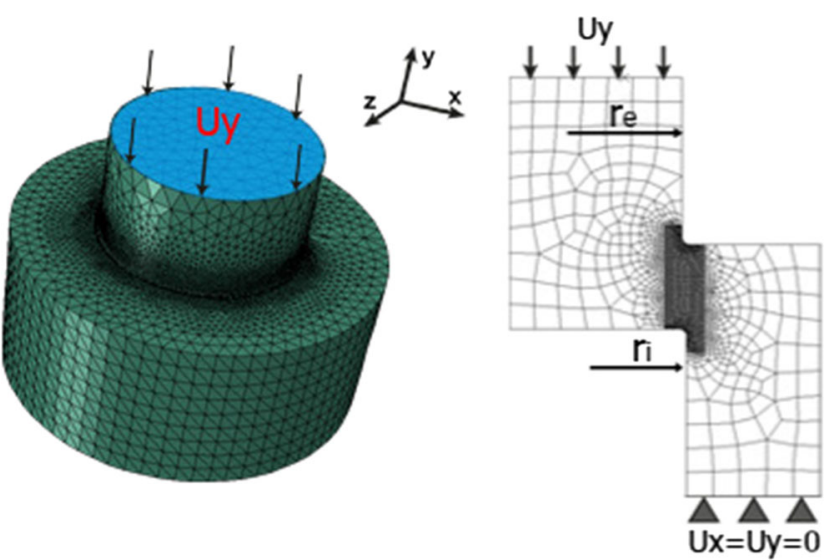

Fig. 10 Modeling of shear test 


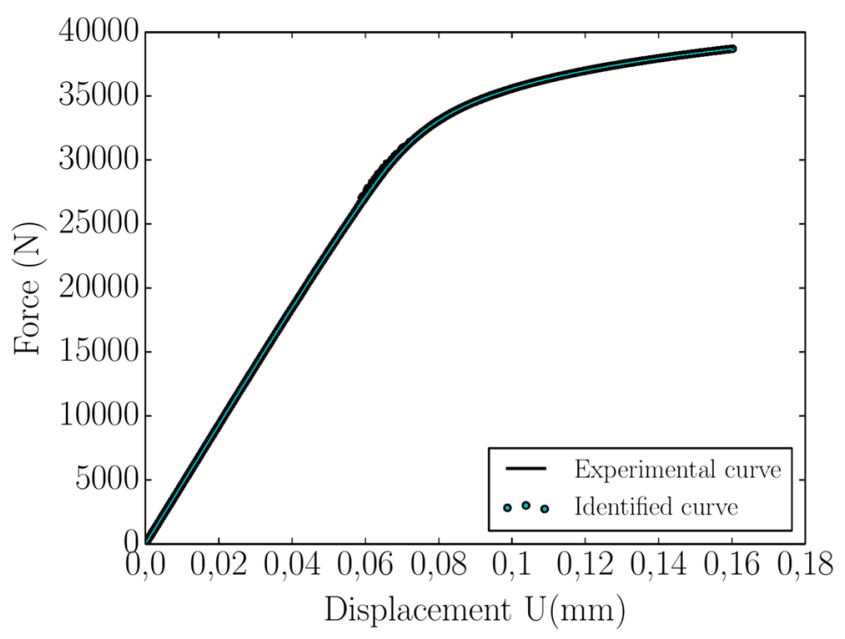

Fig. 11 Comparison of the experimental and identified curves ( $A=1012 \mathrm{MPa}, B=399 \mathrm{MPa}, n=0.22$ )

heat generation via plastic deformation causes the experimental curves to drop. However, the numerical curves continues to increase. Taking into account internal heating by plastic deformation improves the accuracy of the results. In this case, the difference between the experimental and numerical responses does not exceed $4 \%$.

It is also important to note that in order to achieve better results the parameter $C$ should not be considered constant in terms of the strain rate. Table 3 shows the values of the $C$ parameter as a function of the strain rate.

\section{Shear tests}

For the shear tests, hat-shaped specimens have been used. The specimen is loaded in compression along its axis of revolution. This results in the formation of a cylindrical shear zone [8]. In addition, this type of specimen allows the study
Table 4 Variation of parameter $C\left(T=25^{\circ} \mathrm{C}\right)$

\begin{tabular}{llll}
\hline$\dot{\varepsilon}\left(s^{-1}\right)$ & 1 & 10 & 100 \\
\hline $\mathrm{C}$ & 0.028 & 0.028 & 0.035 \\
\hline
\end{tabular}

of strain localization and the formation of shear bands at high strain rates. The thickness of the shear zone is assumed to be constant. The strain rate and the shear stress can be estimated using Eqs. 7 and 8 [21].

$\dot{\gamma}=\frac{V}{e}$

$\tau=\frac{F}{\pi \frac{h\left(d_{i}-d_{e}\right)}{2}}$

Where $\dot{\gamma}$ and $\tau$ art the strain rate and the shear stress, respectively. The parameters $V, e, d_{i}$, and $d_{e}$ represent the impact velocity, the shear zone thickness $e=\left(r_{i}-r_{e}\right)$, and the inner and outer diameter of the specimen.

The identification procedure described above for the compression tests is used for the shear tests. Figure 10 shows the finite element model of the hat-shaped specimens. The model contains 3000 elements and the mesh is refined in the shear zone. The average element size in this area is of the order of $20 \mu \mathrm{m}$.

Firstly, the hardening parameters $(A, B$, and $n)$ have been identified at $\mathrm{T}=25^{\circ} \mathrm{C}$ and $\dot{\varepsilon}=0.1 \mathrm{~s}^{-1}$. Figure 11 shows the results of the identification. It can be seen that very good correlation is obtained between the numerical and the experimental curves (the difference does not exceed $1 \%$ ). The identified parameters are $A=1012 \mathrm{MPa}, B=399 \mathrm{MPa}$, and $n=0.22$

Then, $m$ parameter has been identified for different temperatures. The identification of this parameter is illustrated by Fig. 12a. When the temperature exceeds $600{ }^{\circ} \mathrm{C}$ thermal softening takes place. The same phenomenon has been
Fig. 12 Comparison between the experimental and identified curves: a $m=f(T), \mathbf{b}$ $C=f(\dot{\varepsilon})$

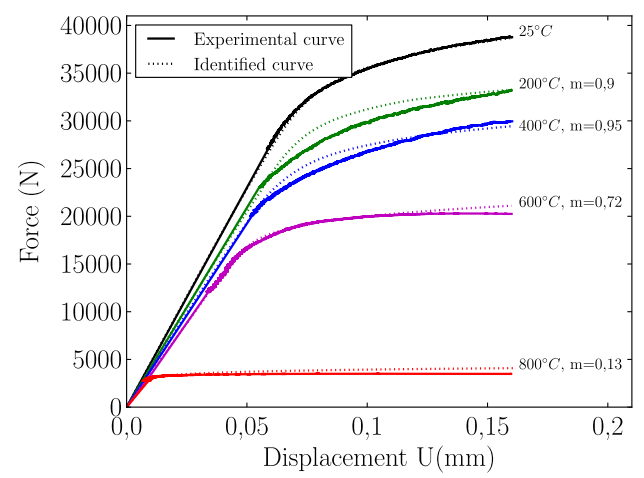

(a)

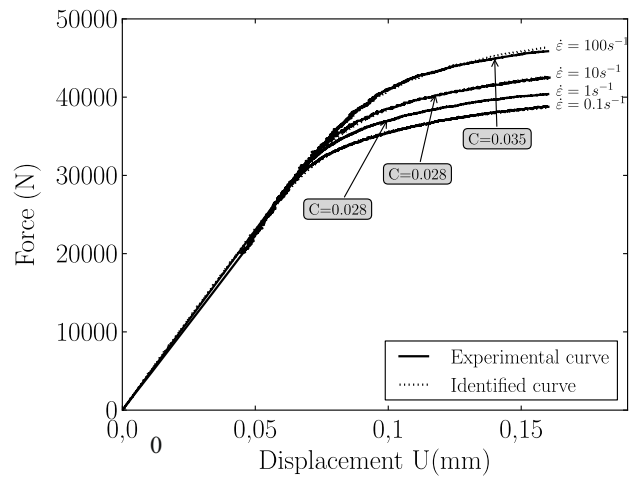

(b) 
Table 5 Variation of parameter $m$

Fig. 13 Compression specimens: a $25^{\circ} \mathrm{C} ; 0.1 \mathrm{~s}^{-1}$, b $25^{\circ} \mathrm{C} ; 1 \mathrm{~s}^{-1}, \mathbf{c} 25^{\circ} \mathrm{C} ; 10 \mathrm{~s}^{-1}, \mathbf{d}$ $400{ }^{\circ} \mathrm{C} ; 0.1 \mathrm{~s}^{-1}$, e $800{ }^{\circ} \mathrm{C}$; $0.1 \mathrm{~s}^{-1}$

Fig. 14 Microscopic observation of a compression specimen $\left(T=600{ }^{\circ} \mathrm{C}\right.$, $\left.\dot{\varepsilon}=0.1 \mathrm{~s}^{-1}\right)$ : Shear band formation

Fig. 15 Microscopic observation of a compression specimen $\left(T=600{ }^{\circ} \mathrm{C}\right.$, $\dot{\varepsilon}=0.1 \mathrm{~s}^{-1}$ ): Microcracks

\begin{tabular}{lcccc}
\hline Temperature ${ }^{\circ} \mathrm{C}$ & 200 & 400 & 600 & 800 \\
\hline $\mathrm{m}$ & 0.9 & 0.95 & 0.72 & 0.13 \\
\hline
\end{tabular}

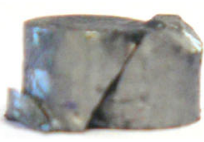

(a)

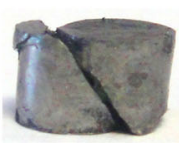

(b)

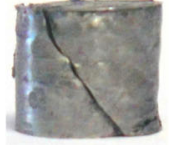

(c)

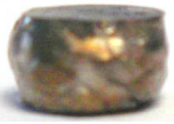

(d)

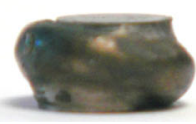

(e)
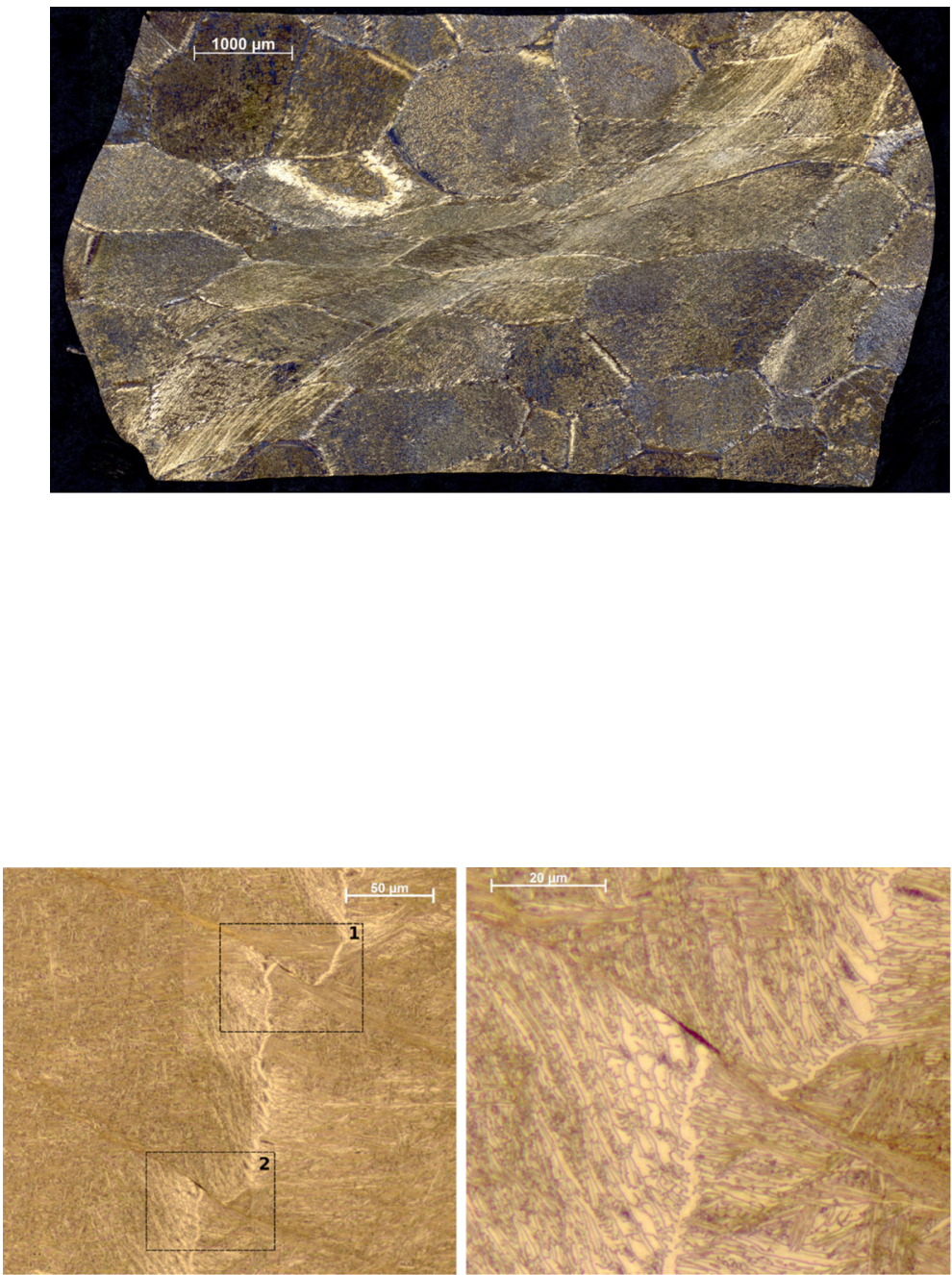


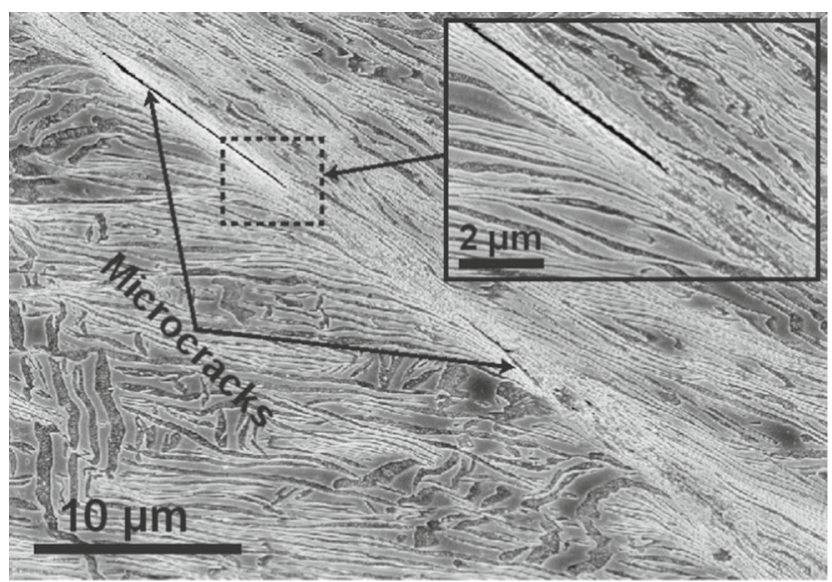

Fig. 16 Microscopic observation of the shear zone $\left(T=400{ }^{\circ} \mathrm{C}, \dot{\varepsilon}=0.1 \mathrm{~s}^{-1}\right)$

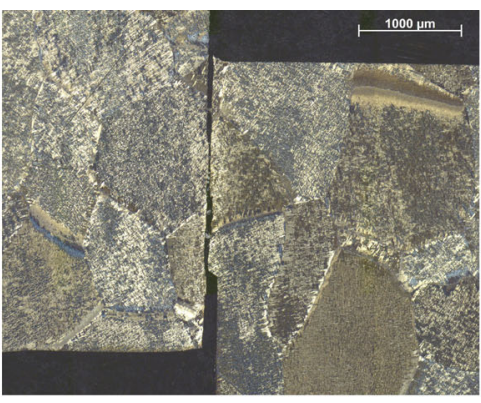

(a) $\mathrm{T}=25^{\circ} C, \dot{\varepsilon}=0.1 \mathrm{~s}^{-1}$

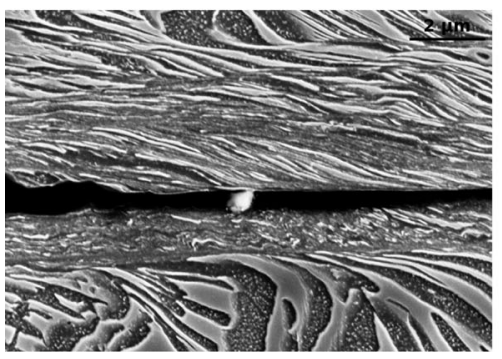

(d) $\mathrm{T}=200^{\circ} \mathrm{C}, \dot{\varepsilon}=0.1 \mathrm{~s}^{-1}$

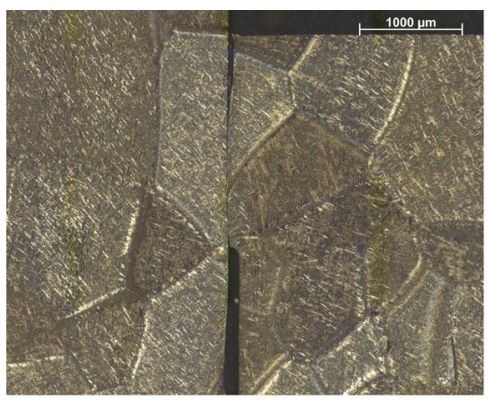

(b) $\mathrm{T}=25^{\circ} \mathrm{C}, \dot{\varepsilon}=10 \mathrm{~s}^{-1}$

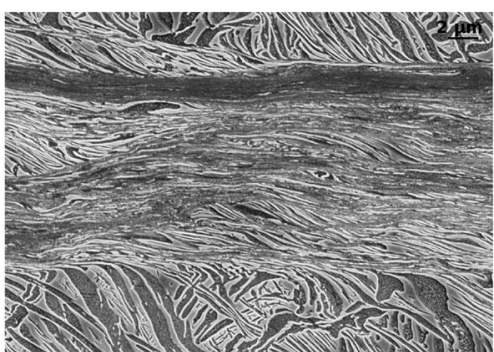

(e) $\mathrm{T}=400^{\circ} C, \dot{\varepsilon}=0.1 \mathrm{~s}^{-1}$

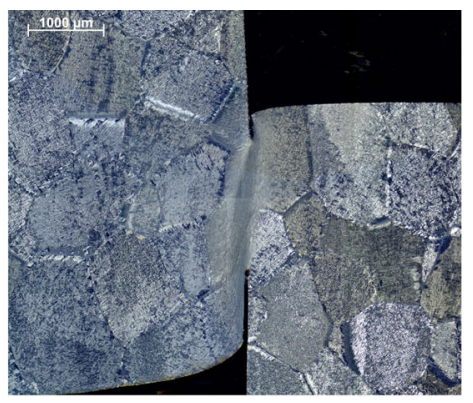

(c) $\mathrm{T}=800^{\circ} \mathrm{C}, \dot{\varepsilon}=0.1 \mathrm{~s}^{-1}$

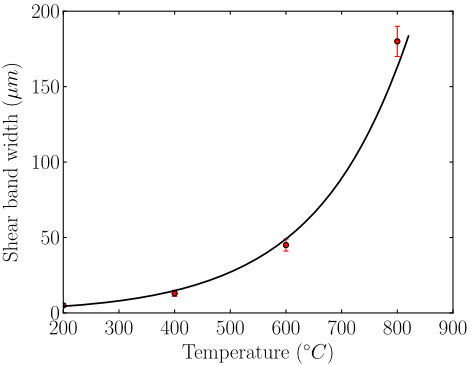

(f) Shear band width evolution

Fig. 17 Microscopic observation of the shear specimens

Fig. 18 Shear test simulation and temperature evolution in the shear band
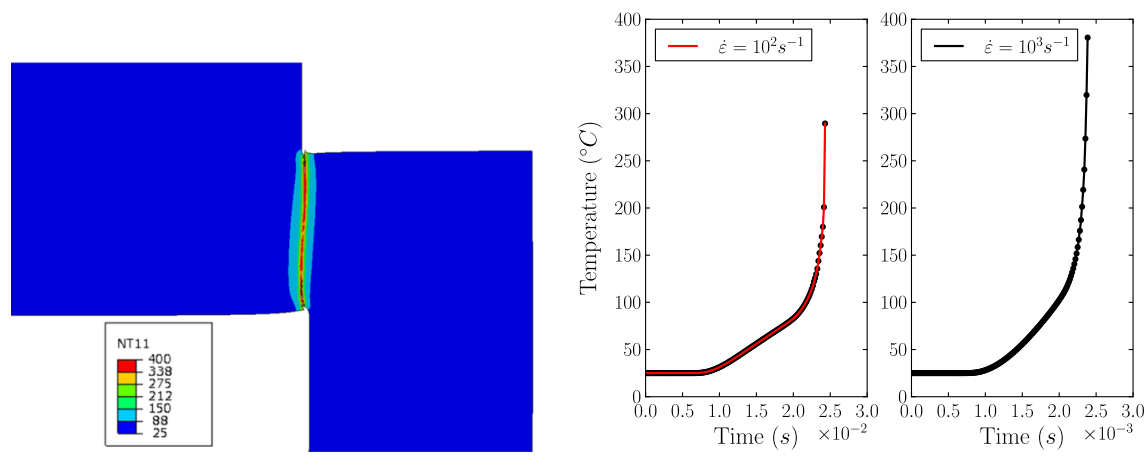


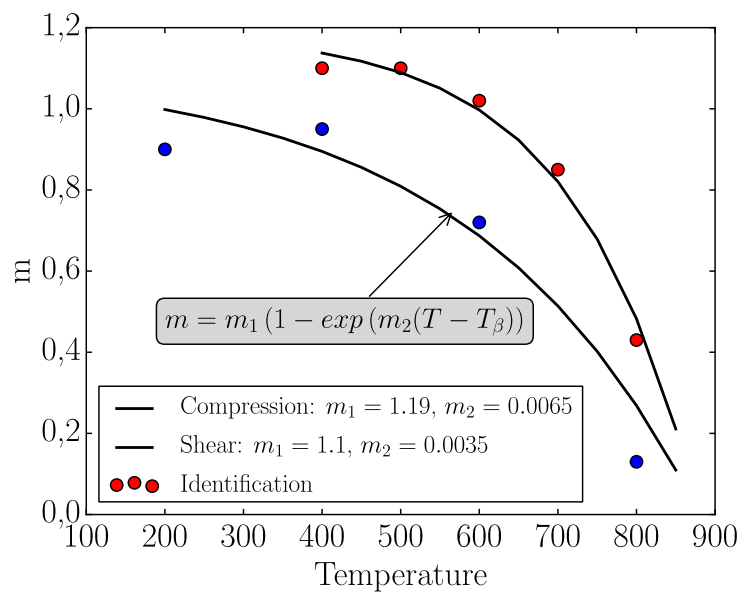

Fig. 19 Evolution of $m$ and $C$ parameters

also observed for the Ti6A14V and the Ti555-3 titanium alloys [4]. Finally, the last step is to identify parameter $C$. Figure $12 \mathrm{~b}$ shows the identified curves.

Tables 4 and 5 summarize the variation of parameter $C$ as a function of strain rate and the parameter $m$ as function of temperature.

\section{Microscopic observations}

Microscopic observations have been conducted on tested specimens. Figure 13 shows five compression specimens tested under various thermo-mechanical conditions.

Figure 14 shows a specimen tested at $600{ }^{\circ} \mathrm{C}$ with strain rate of $\dot{\varepsilon}=0.1 \mathrm{~s}^{-1}$. A very high degree of strain can be seen with the grains being elongated along the diagonal of the specimen. Parallel shear bands can be seen along with the creation of microcracks (Figs. 14 and 15).

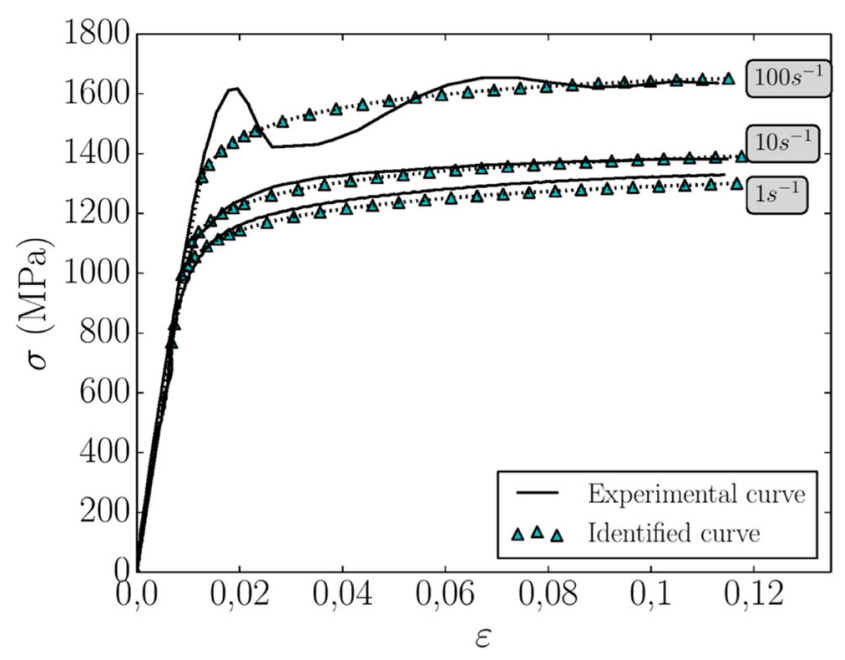

Fig. 20 Model response for different strain rates

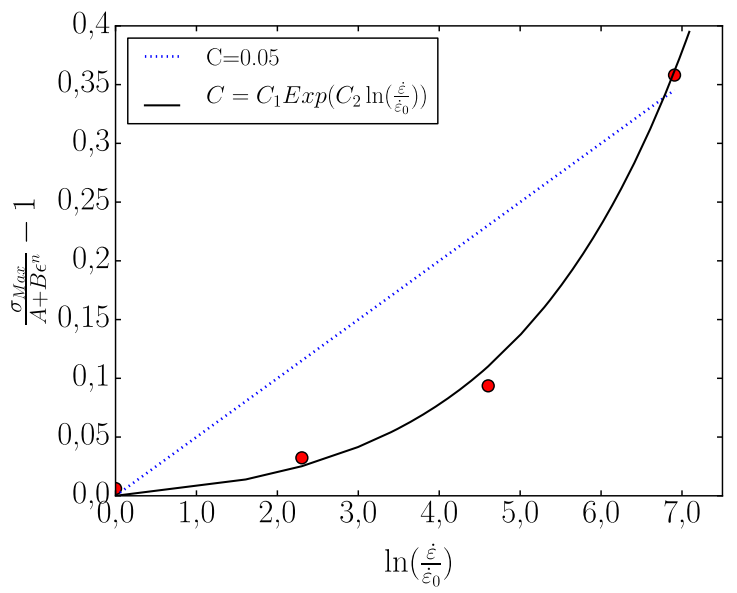

Similar phenomena have been observed at the the temperature of $400{ }^{\circ} \mathrm{C}$ as shown in Fig. 16. The average widthof the shear band is about $7 \mu \mathrm{m}$. In addition, the figure shows microcracks along the shear band. The width of the microcracks is about $140 \mathrm{~nm}$.

With regard to the shear tests, the shear band is highly localized notably at room temperature. However, it becomes larger with the increase of temperature. Figure 17 shows the shear zone for different tests. Figure $17 \mathrm{f}$ demonstrates that the shear band becomes larger depending on the temperature. The dependence of the shear band width of the temperature is illustrated by Fig. 17a-e.

Indeed, for the tests carried out at room temperature and at high strain rates, the temperature generated by plastic deformation reaches $400{ }^{\circ} \mathrm{C}$ (Fig. 18).

\section{Discussion}

Overall, the Johnson-Cook model can adequately reproduce the material behavior under different thermo-mechanical loading conditions. However, the identified parameters are not valid over a wide range of strain rates and temperatures.

Better results are achieved if the model parameters $C$ and $m$ are not considered to be constant. This simple modification is therefore proposed for future studies using the JC model. Indeed, defining parameters $m$ as a function of the temperature and parameter $C$ as a function of strain rate, results in a significant improvement in the model predictions while maintaining the same number of experimental tests and the same identification procedure.

Figure 19 illustrates the evolution of the parameters $m$ and $C$. A model has been proposed to overcome this problem, Fig. 20 shows the model response. With this simple modification, the number of the experimental trials does not change and the result becomes significantly better. 


\section{Conclusion}

The material behavior of the Ti17 titanium alloy loaded under extreme thermo-mechanical conditions has been investigated via compression and shear tests conduced over a large temperature and strain rate range. The tests have shown that the material is sensitive to strain rate and to temperature. The identification of the JohnsonCook (JC) model parameters has been performed using an inverse method. The comparison between the experimental results and the predictions using the JC model highlights some differences, particularly at high strain rates and high temperatures. Micrographic anlysis has shown the evolution, the formation of shear bands and microcracks before the rupture of the specimen. In these areas, the temperature is changing very considerably and can reach $400{ }^{\circ} \mathrm{C}$.

The JC model does not guarantee good prediction accuracy for the thermo-mechanical behavior of the material over a wide range of strain rates and temperatures. It is nevertheless possible to use the model by restricting the range of validity depending on the temperature and strain rates. It is therefore more appropriate to identify the model for different temperature ranges and/or strain rate ranges. This makes it possible to make changes to the model while keeping the same number of tests and the same identification method. This, significantly improve the prediction accuracy of the model. Indeed, a simple evolution of the parameters $m$ and $C$ improves the response of the model. A change in these parameters has been proposed in this work.

For an enhanced reproduction of the material behavior, it might be better to use a crystal plasticity law. However, the identification of the constitutive equation parameters is much more complicated as well as the implementation in FEA computer codes.

Acknowledgments Authors would like to thank the French Région des Pays de la Loire and the company Timet (Ugine-France) for funding the project.

\section{References}

1. Abukhshim N, Mativenga P, Sheikh M (2006) Heat generation and temperature prediction in metal cutting: a review and implications for high speed machining. Int J Mach Tools Manuf 46(7-8):782800

2. Ayed Y, Robert C, Germain G, Ammar A (2016) Development of a numerical model for the understanding of the chip formation in high-pressure water-jet assisted machining. Finite Elem Anal Des 108:1-8

3. Baker M, Rosler J, Siemers C (2003) The influence of thermal conductivity on segmented chip formation. Comput Mater Sci 26:175-182

4. Braham-Bouchnak T (2010) Etude du comportement en sollicitations extrêmes et l'usinabilité d'un nouvel alliage de titane aéronautique : le ti555-3. Ph.D. thesis, ENSAM
5. Brown S (1987) An internal variable constitutive model fir the hot working of metals. Ph.D. thesis, MIT

6. Cadoni E, Fenu L, Forni D (2012) Strain rate behaviour in tension of austenitic stainless steel used for reinforcing bars. Construct Build Mater 35:399-407

7. Calamaz M, Coupard D, Girot F (2008) A new material model for $2 \mathrm{~d}$ numerical simulation of serrated chip formation when machining titanium alloy ti-6al-4v. Int J Mach Tools Manuf 48(3-4):275288

8. Changeux B (2001) Loi de comportement pour l'usinage. Localisation de la déformation et aspects microstructuraux. Ph.D. thesis, ENSAM

9. Clausen A, Borvik T, Hopperstad O, Benallal A (2004) Flow and fracture characteristics of aluminium alloy AA5083-H116 as function of strain rate, temperature and triaxiality. Mater Sci Eng A 364(1-2):260-272

10. Ducobu F, Riviere-Lorphevre E, Filippi E (2016) Material constitutive model and chip separation criterion influence on the modeling of ti6al $4 \mathrm{v}$ machining with experimental validation in strictly orthogonal cutting condition. Int J Mech Sci 107:136-149

11. Habak M (2006) Etude de l'influence de la microstructure et des paramètres de coupe sur le comportement en tournage dur de l'acier roulement $100 \mathrm{cr} 6$. Ph.D. thesis, ENSAM

12. He A, Xie G, Zhang H, Wang X (2013) A comparative study on Johnson-Cook, modified Johnson-Cook and arrhenius-type constitutive models to predict the high temperature flow stress in 20crmo alloy steel. Mater Des 52:677-685

13. Hou QY, Wang JT (2010) A modified Johnson-Cook constitutive model for mg-gd-y alloy extended to a wide range of temperatures. Comput Mater Sci 50(1):147-152

14. Hor A (2011) Simulation physique des conditions thermomécaniques de forgeage et d'usinage - caractérisation et modélisation de la rhéologie et de l'endommagement. Ph.D. thesis, ENSAM

15. Johnson G, Cook W (1983) A constitutive model and data for metals subjected to large strains, high strain rates and temperature. In: 7th International Symposium on ballistics

16. Cheng K, Huo D (2013) Micro-cutting: fundamentals and applications:2013

17. Li H, Wang X, Duan J, Liu J (2013) A modified johnson cook model for elevated temperature flow behavior of $\mathrm{t} 24$ steel. Mater Sci Eng A 577:138-146

18. List G, Sutter G, Bouthiche A (2012) Cutting temperature prediction in high speed machining by numerical modelling of chip formation and its dependence with crater wear. Int J Mach Tools Manuf 54-55:1-9

19. Ludwik P (1909) Elemente der technologischen mechanik. Springer Verlag

20. Lurdos O (2008) Lois de comportement et recristallisation dynamique: approches empirique et physique. Ph.D. thesis, Ecole Nationale Supérieure des Mines de Saint-Etienne

21. Meyers M, Subhash G, Kad B, Prasad L (1994) Evolution of microstructure and shear-band formation in $\alpha$-hcp titanium. Mech Mater 17(2-3):175-193

22. Meyers M, Xu Y, Xue Q, Pérez-Prado M., McNelley T (2003) Microstructural evolution in adiabatic shear localization in stainless steel. Acta Mater 51(5):1307-1325

23. Mirza F, CHEN D, LI D, ZENG X (2013) A modified JohnsonCook constitutive relationship for a rare-earth containing magnesium alloy. J Rare Earths 31(12):1202-1207

24. M'saouibi R (1998) Aspects thermiques et microstructuraux de la coupe. Application Aă la coupe orthogonale des aciers austénitiques. Ph.D. thesis, ENSAM

25. Pan H, Liu J, Choi Y, Xu C, Bai Y, Atkins T (2016) Zones of material separation in simulations of cutting. Int J Mech Sci 115116:262-279 
26. Pujana J, Campo L, Pérez-Sáez R., Gallego M, Arrazola PJ (2008) Radiation thermometry applied to temperature measurement in the cutting process. Meas Sci Technol 202(1-3):475-485

27. Rohr I, Nahme H, Thoma KJr, CA (2008) Material characterisation and constitutive modelling of a tungsten-sintered alloy for a wide range of strain rates. Int J Impact Eng 35(8):811819

28. Samantaray D, Mandal S, Bhaduri A (2009) A comparative study on johnson cook, modified zerilli-armstrong and arrhenius-type constitutive models to predict elevated temperature flow behaviour in modified 9cr-1mo steel. Comput Mater Sci 47(2):568-576

29. Scapin M, Peroni L, Peroni M (2012) Parameters identification in strain-rate and thermal sensitive visco-plastic material model for an alumina dispersion strengthened copper. Int J Impact Eng 40-41:58-67

30. Schonberg WP, Kupchella R, Stowe D, Xiao X, Algoso A, Cogar J (2015) Proceedings of the 2015 hypervelocity impact symposium (hvis 2015) incorporation of material variability in the johnson cook model. Procedia Eng 103:318-325

31. Taylor G, Quinney H (1934) The latent energy remaining in a metal after cold working. Proc Roy Soc:307-326
32. Teixeira J (2005) Etude expérimentale et modélisation des évolutions microstructurales au cours des traitements thermiques post forgeage dans l'alliage de titane ti17. Ph.D. thesis, Institut National Polytechnique de Lorraine

33. Teng X, Wierzbicki T (2006) Evaluation of six fracture models in high velocity perforation. Eng Fract Mech 73(12):1653-1678

34. Wierzbicki T, Bao Y, Lee Y-W, Bai Y (2005) Calibration and evaluation of seven fracture models. Int J Mech Sci 47(4-5):719-743

35. Yaich M, Ayed Y, Bouaziz Z, Germain G (2016) Numerical analysis of constitutive coefficients effects on fe simulation of the $2 d$ orthogonal cutting process: application to the ti6al4v. Int J Adv Manuf Technol 1-21

36. Zerilli F, Armstrong R (1988) Dislocation-mechanics-based constitutive relations for material dynamics calculations. J Appl Phys 61:1816-1825

37. Zhao H (1997) A constitutive model for metals over a large range of strain rates identification for mild-steel and aluminium sheets. Mater Sci Eng A 230(1-2):95-99

38. Zhang D-N, Shangguan Q-Q, Xie C-J, Liu F (2015) A modified Johnson-Cook model of dynamic tensile behaviors for 7075-t6 aluminum alloy. J Alloys Compd 619:186-194 